\title{
Recruiting first-degree relatives for prevention research: a comparison of clinician and proband-led methods of contact in Crohn's disease
}

\author{
Erin P Reid ${ }^{1}$, Alastair Forbes ${ }^{2,5}$, Jeremy Sanderson ${ }^{3}$, Christopher G Mathew ${ }^{4}$, Cathryn Lewis ${ }^{4}$ \\ and Theresa M Marteau*,1
}

${ }^{1}$ King's College London, Department of Psychology, Health Psychology Section, Institute of Psychiatry, London, UK; ${ }^{2}$ St
Mark's Hospital, Harrow, Middlesex, UK; ${ }^{3}$ Guy's and St Thomas' Hospital Trust, St Thomas ' Hospital, London, UK;
${ }^{4}$ King's College London School of Medicine, Guy's Hospital, London, UK; ${ }^{5}$ University College London, London, UK

The most effective and acceptable ways of approaching relatives of identified probands to participate in research are unknown. We report on two methods. A total of 640 probands with Crohn's disease were contacted by post and invited to select how the research team would contact their relatives to assess their interest in participating in prevention research. Clinician-led approach: required probands to provide contact details for their first-degree relatives so that the research team could send them study questionnaires; proband-led approach: required probands to request questionnaires with stamped envelopes for them to forward to their relatives. Fifty-six percent $(356 / 640)$ of probands contacted participated, with $80 \%$ (284) providing details of eligible relatives. Forty-eight percent $(136 / 284)$ of probands requested 392 relatives be contacted by the researchers and $50 \%(142 / 284)$ requested that the questionnaire be sent to them so that they could give this to their 437 relatives personally. Two percent $(6 / 284)$ requested mixed methods. Eligible responses came from $73 \%$ of relatives $(587 / 805), 81 \%$ $(299 / 368)$ of those contacted by the researchers and $66 \%(288 / 437)$ of those contacted via probands (difference $15 \%, 95 \% \mathrm{Cl} 10,22$ ). Both methods yielded similarly high levels of interest from relatives in participating in prevention research $(89 \%(265 / 299)$ direct; $86 \%(248 / 288)$ indirect). Direct clinician-led contact maximised response rates. High levels of interest in research across the two recruitment methods suggest that although proband-led methods may maximise privacy, they may deny relatives the opportunity to take part in research that would be of interest.

European Journal of Human Genetics (2006) 14, 1263-1268. doi:10.1038/sj.ejhg.5201699; published online 26 July 2006

Keywords: Crohn's disease; family-based research; research recruitment; ethics; genetics

\section{Introduction}

Genetic-related epidemiological and behavioural studies often require recruitment of relatives of identified pro-

*Correspondence: Professor TM Marteau, King's College London, Department of Psychology, Health Psychology Section, Institute pf Psychiatry, 5th Floor Thomas Guy House, Guy's Campus, London SE1 9RT, UK.

Tel: +440207188 0192; Fax: + 440207188 0195;

E-mail: theresa.marteau@kcl.ac.uk

Received 22 December 2005; revised 14 June 2006; accepted 16 June 2006; published online 26 July 2006 bands. The most effective and acceptable ways of approaching such relatives is the subject of some uncertainty and controversy. ${ }^{1,2}$ A central tension lies in the desire to maximise recruitment while protecting relatives' privacy.

Beskow et al ${ }^{1}$ suggest that all recruitment methods lie on a continuum between maximising accrual, typically associated with contact being made directly by the researchers, and maximising privacy, seen as the key advantage of indirect contact methods in which the contact with relatives is made directly by the proband. Newson and 
Humphries, ${ }^{2}$ however, argue that direct contact methods not only increase response rates, but they also increase the accuracy of information received by researchers. In addition, direct contact methods may avoid the potential psychological harm to the proband brought about through discussing the risks of their relatives developing their heritable condition. There are, however, few data to support either of these view points.

When relatives are approached directly by researchers, researchers having obtained contact names and addresses from probands, response rates tend to be higher than those in which relatives are contacted indirectly, that is, with probands making the contact. ${ }^{3-6}$ Studies that have reported using these two approaches are limited in several ways. First, few provide information on the numbers of probands approached in order to recruit a given number of relatives. ${ }^{6,7}$ Such information is important for those attempting to estimate the proband population needed to achieve a given study sample size. Second, there have been few, if any, studies in which researcher or proband-led methods of recruitment have been compared. We report here an observational study in which we invited probands with Crohn's disease to select one of the two methods by which their first degree relatives (FDRs) could be contacted with a request for them to complete a brief questionnaire assessing their interest in participating in research aimed at preventing Crohn's disease. We hypothesised that clinician-led contact results in a higher response rate than proband-led contact.

The study sample comprised probands with Crohn's disease and their FDRs. Crohn's disease is a complex condition with a population prevalence of between 1.4 per 1000 per lifetime ${ }^{8}$ and 3.8 per 1000 by age $30 .^{9}$ FDRs of those diagnosed with Crohn's disease have a 10-fold increased risk of developing the condition compared to population-based incidence rates. ${ }^{10}$

Although the disease is not preventable, it is hypothesised that the risk of developing the disease in those at increased risk may be reduced by diet, ${ }^{11}$ antibiotics, ${ }^{12}$ probiotics $^{13}$ and smoking cessation. ${ }^{14}$ Smoking is associated with a three- to four-fold increase in the risk of developing Crohn's disease, ${ }^{15}$ and leads to a more aggressive course in those with the disease, a pattern that is reversed by smoking cessation. ${ }^{16}$

A further aim of the current study was to estimate the number of probands with Crohn's disease that would need to be contacted in order to recruit into a clinical trial 630 smokers who are FDRs of probands with Crohn's disease (http://www.iop.kcl.ac.uk/grab/).

\section{Materials and methods}

Ethics committee approval was sought and granted for the investigation (04/Q0702/59). Between December 2004 and
March 2005, 640 probands with Crohn's disease attending one of the two hospitals were contacted by post and invited to consent to their FDRs being contacted to complete a brief questionnaire to ascertain their level of interest in participating in prevention research. It was explained that eligible relatives were parents, siblings or children, aged over 18 years, living in the British Isles and without a diagnosis of Crohn's disease or ulcerative colitis.

Probands were invited to select one of the two ways in which their relatives could be contacted:

- Direct approach by the consultant gastroenterologist providing their care, requiring the proband to provide the names and addresses of their FDRs for the clinician to send them study questionnaires.

- Proband-led approach, requiring the proband to request a number of questionnaires with stamped envelopes for them to forward to their relatives. The letters sent to both probands and their FDRs were signed by the consultant running the clinic, which provided clinical care for the proband.

Copies of all the study materials can be obtained from the corresponding author.

\section{Relatives' questionnaire}

The letter and study information sheet sent to the relatives that accompanied the questionnaire named their relative (the proband) who had either passed their details to the clinician signing the letter or who had passed the details directly to the relative. The letter stated that Crohn's disease tends to run in families and stated that the purpose of the survey was to assess relatives' interest in participating in research to learn more about their risks of developing the disease and possible ways of reducing these risks. Those with questions or concerns were invited to telephone the consultant gastroenterologist who sent the letter. Although no probands or FDRs contacted the consultant gastroenterologists with study-related questions or queries, seven FDRs wrote to their relative's consultant gastroenterologist to inform them of deceased probands.

The questionnaire consisted of 10 questions designed to ascertain levels of interest in the planned Crohn's disease prevention research. In addition, general health and demographic information was requested (see Table 1 for details).

The planned research comprised two Crohn's disease prevention studies. The first study focused on assessing FDRs' risk of developing Crohn's disease and providing salient lifestyle advice on how that risk might be reduced (Study I). The second study focused on FDRs making Crohn's disease preventative changes to their diet, or 
Table 1 Demographic characteristics of responding relatives

\begin{tabular}{|c|c|c|c|c|c|c|}
\hline \multirow{3}{*}{ Variable } & \multicolumn{6}{|c|}{ Method of contact } \\
\hline & \multicolumn{2}{|c|}{ Researcher $(\mathrm{n}=299)$} & \multicolumn{2}{|c|}{ Proband $(\mathrm{n}=288)$} & \multicolumn{2}{|c|}{ Total $(\mathrm{n}=587)$} \\
\hline & $\mathrm{n}$ & $\%$ & $\mathrm{n}$ & $\%$ & $\mathrm{n}$ & $\%$ \\
\hline \multicolumn{7}{|l|}{ Gender } \\
\hline Male & 124 & 41.5 & 114 & 39.6 & 238 & 40.5 \\
\hline Female & 175 & 58.5 & 174 & 60.4 & 349 & 59.5 \\
\hline Age: Mean (s.d.) & \multicolumn{2}{|c|}{$48.4(15.86)$} & \multicolumn{2}{|c|}{$45.3(15.95)$} & \multicolumn{2}{|c|}{$46.9(15.97)$} \\
\hline \multicolumn{7}{|l|}{ Education } \\
\hline Up to GCSE & 127 & 42.5 & 148 & 51.4 & 275 & 46.8 \\
\hline Above GCSE & 170 & 56.9 & 139 & 48.3 & 309 & 52.6 \\
\hline Missing & 2 & 0.7 & 1 & 0.3 & 3 & 0.5 \\
\hline \multicolumn{7}{|l|}{ Self-defined level of health } \\
\hline Excellent & 42 & 14 & 43 & 14.9 & 85 & 14.5 \\
\hline Very good & 115 & 38.5 & 122 & 42.4 & 237 & 40.4 \\
\hline Good & 96 & 32.1 & 83 & 28.8 & 179 & 30.5 \\
\hline Fair & 39 & 13 & 38 & 13.2 & 77 & 13.1 \\
\hline Poor & 6 & 2 & 2 & 0.7 & 8 & 1.4 \\
\hline Missing & 1 & 0.3 & - & - & 1 & 0.2 \\
\hline \multicolumn{7}{|l|}{ Number of times exercise in a week } \\
\hline 0 & 76 & 25.4 & 70 & 24.3 & 146 & 24.9 \\
\hline 1 & 61 & 20.4 & 58 & 20.1 & 119 & 20.3 \\
\hline $2-4$ & 121 & 40.5 & 126 & 43.8 & 247 & 42.1 \\
\hline $5+$ & 40 & 13.4 & 34 & 11.8 & 74 & 12.6 \\
\hline Missing & 1 & 0.3 & - & - & 1 & 0.2 \\
\hline \multicolumn{7}{|l|}{ Current smoking status } \\
\hline Smoker & 56 & 18.7 & 63 & 21.9 & 119 & 20.3 \\
\hline Non-smoker & 243 & 81.3 & 225 & 78.1 & 468 & 79.7 \\
\hline Number of cigarettes smoked daily & $(n=56)^{\mathrm{a}}$ & & $(n=63)$ & & $(n=11 \mathrm{~s}$ & \\
\hline $40+$ & 2 & 3.6 & - & - & 2 & 1.7 \\
\hline $31-40$ & 1 & 1.8 & 4 & 6.3 & 5 & 4.2 \\
\hline $21-30$ & 7 & 12.7 & 11 & 17.5 & 18 & 15.3 \\
\hline $11-20$ & 23 & 41.8 & 25 & 39.7 & 48 & 40.7 \\
\hline Below 10 & 22 & 40.0 & 23 & 36.5 & 45 & 38.1 \\
\hline
\end{tabular}

${ }^{\mathrm{a}}$ Missing $(n=1)$.

${ }^{\mathrm{b}}$ General certificate of secondary education.

taking medicines linked to Crohn's disease prevention (Study II).

Both the Crohn's disease probands and their unaffected relatives were offered the opportunity to receive a summary of the results of this study. Seventy-one percent (252/ 356 ) of the responding Crohn's disease probands and $83 \%$ $(508 / 614)$ of the responding relatives requested the summary which was then posted to them.

\section{Results}

Probands' responses

Responses were received from 56\% (356/640) of the probands contacted. Gender was the only variable we had on all 640 probands in order to assess representativeness of responders. Women were more likely than men to respond
(240/381 (63\%) vs 116/259 (45\%); $\chi^{2}$ (1) 20.70: $P<0.0001$ ). Of those responding, $284(80 \%)$ probands provided details of relatives that met the inclusion criteria. Forty-eight percent $(136 / 284)$ requested that their 392 relatives be sent questionnaires directly by the researchers and $50 \%$ $(142 / 284)$ requested that the questionnaires be sent to them so that they could pass them onto their 437 relatives. Two percent $(6 / 284)$ requested a mixture of the two methods.

Figure 1 provides details of responses at each stage of the study.

The 356 responding probands generated 829 relatives, of whom 805 were eligible for the studies. Forty-six percent of these relatives (368/805) were then contacted directly by the researchers and 54\% (437/805) indirectly, via the proband. 


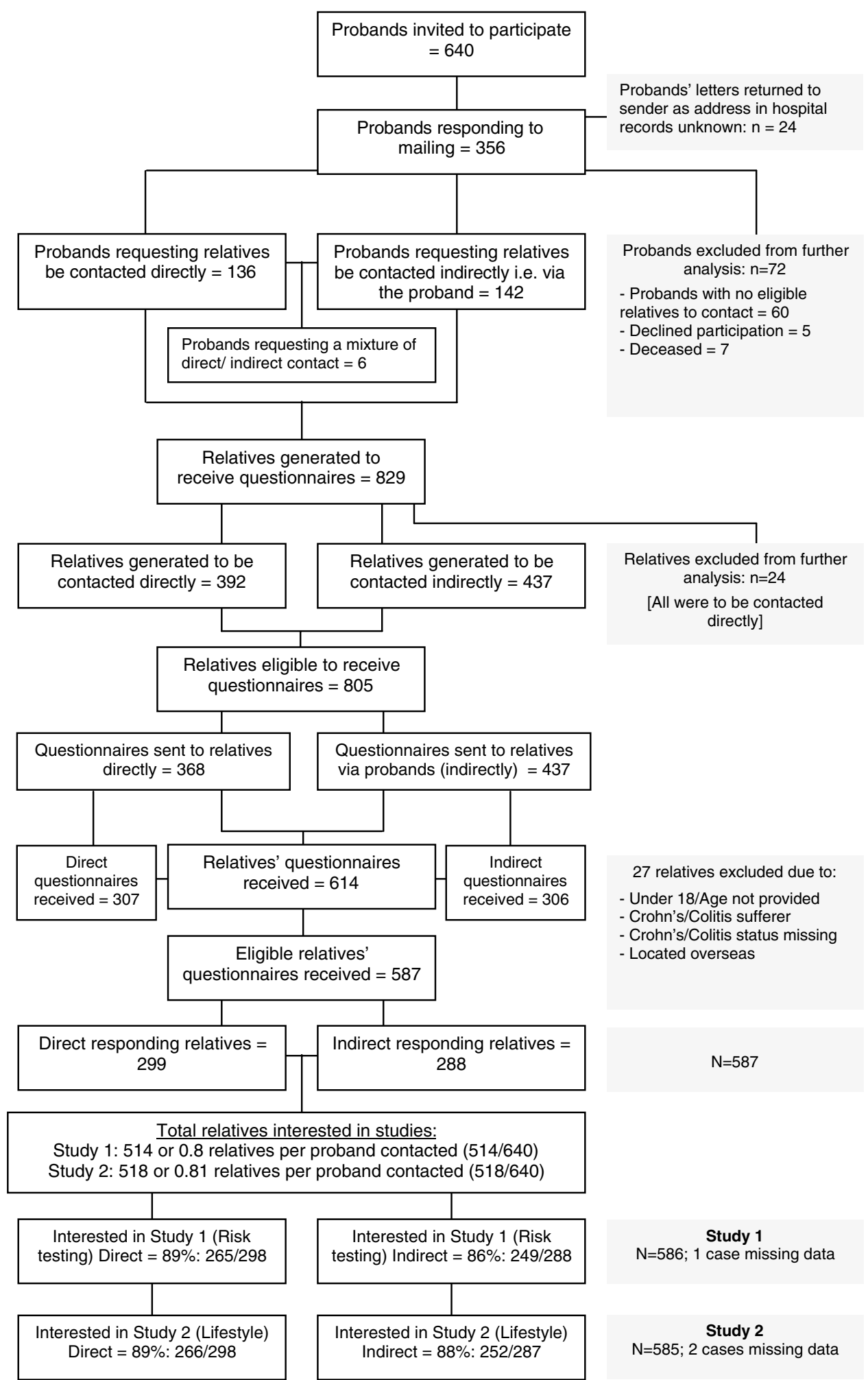

Figure 1 Diagram showing flow of probands and relatives through the study. 


\section{Relatives' responses}

Six hundred and fourteen out of 805 (76\%) relatives responded, of whom 587 provided eligible responses. Eighty-one percent (299/368) of relatives contacted directly by the researchers responded, compared with $66 \%$ (288/437) of those contacted indirectly via their affected relatives (difference 15\%, 95\% CI 10, 22).

The characteristics of the responding relatives are shown in Table 1 . Those responding via the two methods of recruitment were compared on the seven characteristics listed in Table 1 , using $\chi^{2}$ tests for all variables, except age, for which $t$-tests were used. The only difference occurred in terms of education: those responding via the researcher-led method were more likely to be educated to a higher level ( $\chi^{2}$ (1) $\left.4.54 ; P=0.038\right)$.

Overall, 88\% (Study I: 514/586; Study II: 518/585) of responders expressed interest in learning more about the two planned prevention research studies, 6\% (Study I: 33/ 586; Study II: 35/585) wanted further information before making a decision, and 6\% (Study I: 39/586; Study II: 32/ 585) were not interested in participating in the research. There was no difference in the level of interest expressed by respondents contacted directly by the researchers compared with those contacted via their family member: 89\% (Study I: 265/298; Study II: 266/298) of responders who were contacted directly expressed interest in the research, compared to more than $86 \%$ (Study I: 249/288; Study II: 252/287) of those responders contacted indirectly.

Twenty percent $(119 / 587)$ of the FDRs interested in participating in the planned research studies were smokers; $90 \%(107 / 119)$ of the smokers were interested in participating in the risk assessment study (Study I), whereas $88 \%$ $(105 / 119)$ were interested in taking part in the lifestyle change study (Study II).

\section{Discussion}

Contacting 640 probands with Crohn's disease resulted in responses from 587 FDRs unaffected by the disease. Of these, over $85 \%$ were interested in participating in research aimed at preventing the disease. Thus, for every 100 probands contacted, interest in participating in prevention research was expressed by 80 FDRs, of whom 22 were smokers. Further similar studies conducted with other proband groups inviting relatives to take part in different types of studies will allow the generation of reliable estimates of use to those planning research on 'at-risk' relatives of those identified with a disease.

As predicted, direct contact from a clinician resulted in higher response rates than those achieved when probands contacted their relatives themselves. There are several possible explanations for this. First, fewer relatives may have received information about the study when probands took the initiative to make the contact. Second, probands may have selected to contact relatives themselves that they perceived as less likely to respond positively either to being contacted directly by clinicians or more generally to participation in the research. Thus, the different response rates obtained using the two methods of contact may reflect differences in the relatives contacted via the two methods, not differences attributable to the two methods per se. It seems likely that both of these possible explanations contributed to the lower response rates from relatives contacted via a family member. It would be useful in future studies to ask probands why they selected one method of contact over another, and why those responding following contact via each method did so. This would also shed light on the extent to which the signatory of the letter is influencing responses.

Given our speculation about the factors that contributed to the lower response rates in the proband-led method of approach, there are two possible ways to maximise responses from relatives contacted via a family member. First, a reminder could be sent to probands: whereas some may have decided not to pass on the information to their unaffected relatives, others may not have made such a decision, and are a group for whom an appropriately worded reminder could prompt action. Second, given the results of the current study, it might be possible to provide some reassurance to probands that many relatives welcome information about opportunities to participate in salient research.

The similarly high levels of interest in research among the responders recruited using the two methods suggests that although family-led methods may maximise privacy, they may deny some relatives the opportunity to take part in research that would have been of interest to them. Not all probands want to give their relatives' details to their clinicians for the latter to make an initial contact about participating in research. The results of the current study suggest that by offering this as an option alongside proband-led contact, recruitment will be maximised, particularly if reminders and reassurance can be offered to probands initiating the contact. We did not assess the potential adverse psychological impact of contacting relatives. When assessed in the context of inviting relatives via probands for screening, the great majority of relatives were content about such contact. ${ }^{17}$ We received no complaints from relatives approached using either method, an admittedly crude index of harm. More sensitive measures and designs are, however, needed to assess the potential harms in both methods of approaching relatives, harms that may be incurred by the relative and the proband. In addition to potential harm, contacting relatives has potential benefits for these relatives. This was evident in the extremely positive responses received from many relatives who wanted to participate in research as well as to learn more about their risk status. 
As would be expected, not all probands or relatives responded to the study. Responding probands were more likely to be women. This may reflect the role of genetic housekeeper, which women have been described as assuming in health contexts. The relatives that responded when recruited via the two methods were similar on six out of seven characteristics. They differed, however, in their levels of education with those recruited having received their invitation directly from clinicians having a higher level of education than those recruited via probands. There are two possible explanations. First, the two groups of relatives had similar levels of education, but those with higher levels of education were more inclined to respond to a letter sent from a clinician. Alternatively, probands with lower levels of education or who had relatives with lower levels of education were more likely to opt for contacting their relatives themselves.

The extent to which the results of this study generalise to contacting probands with Crohn's disease in other clinics or countries is unknown. The current study was conducted among probands receiving care for their disease in two hospitals. The response rates were the same from probands and their relatives in the two hospitals, suggesting that the results may be generalisable to other clinics at least in the UK. We do not know the extent to which the results of the current study will generalise to studies involving those affected by other conditions. It seems likely that probands may be less willing to contact their relatives for conditions that are relatively stigmatising. These would include mental illnesses. As bowel conditions tend to be relatively stigmatised, it is possible that the current study underestimates the response that would be achieved from approaching probands with a less stigmatised condition such as heart disease. Probands may also be less willing to contact relatives for conditions for which there is no cure or treatment and little prospect of this changing. This would include Huntington's disease and Alzheimer's disease. The extent to which any unwillingness may stem from a sense of 'genetic guilt' is also unknown.

Understanding more about probands' attitudes towards contacting their relatives and the barriers to them doing so is important in informing those who need to recruit relatives of probands of the most effective and sensitive methods of doing this. Although the results of the current study suggest this may be clinician-led methods, uncertainty remains.

\section{Acknowledgements}

We are grateful to all of the Crohn's disease probands and their relatives who assisted with this survey.

\section{References}

1 Bestow L, Botkin J, Daly M et al: Ethical issues in identifying and recruiting participants for familial genetic research. Am J Med Genet 2004; 130A: 424-431.

2 Newson AJ, Humphries SE: Cascade testing in familial hypercholesterolaemia: how should family members be contacted? Eur J Hum Genet 2005; 13: 401-408.

3 Lerman C, Seay J, Balshem A, Audrain J: Interest in genetic testing among first-degree relatives of breast cancer patients. Am J Med Genet 1995; 57: 385-392.

4 Rimer B, Schildkraut JM, Lerman C, Lin TH, Audrain J: Participation in a women's breast cancer risk counseling trial. Who participates? Who declines? High Risk Breast Cancer Consortium. Cancer 1996; 77: 2348-2355.

5 Sorenson JR, Jennings-Grant T, Newman J: Communication about carrier testing within hemophilia A families. Am J Med Genet 2003; 119C: 3-10.

6 Bratt O, Damber JE, Emanuelsson $\mathrm{M}$ et al: Risk perception screening practice and interest in genetic testing among unaffected men in families with hereditary prostate cancer. Eur J Cancer 2000; 36: 235-241.

7 Marteau T, Senior V, Humphries SE et al: Psychological impact of genetic testing for familial hypercholesterolemia within a previously aware population: A randomized controlled trial. Am J Med Genet 2004; 128A: 285-293.

8 Loftus Jr EV, Silverstein MD, Sandborn WJ, Tremaine WJ Harmsen WS, Zinsmeister AR: Crohn's disease in Olmsted County, Minnesota, 1940-1993: incidence, prevalence, and survival. Gastroenterology 1998; 114: 1161-1168.

9 Ehlin AG, Montgomery SM, Ekbom A, Pounder RE, Wakefield AJ: Prevalence of gastrointestinal diseases in two British national birth cohorts. Gut 2003; 52: 1117-1121.

10 Achkar JP, Lashner BA: Genetics of inflammatory bowel disease. Med Gen Med 2002; 4 (2).

11 Gibson PR, Shepherd SJ: Personal view: food for thought western lifestyle and susceptibility to Crohn's disease. The FODMAP hypothesis. Allied Parmacol Ther 2005; 21: 1399-1409.

12 Kruis W: Review article: antibiotics and probiotics in inflammatory bowel disease. Aliment Pharmacol Ther 2004; 20: 75-78.

13 Dunne C: Adaptation of bacteria to the intestinal niche: probiotics and gut disorder. Inflamm Bowel Dis 2001; 7: 136-145.

14 Regueiro M, Kip KE, Cheung O, Hegazi RA, Plevy S: Cigarette smoking and age at diagnosis of inflammatory bowel disease. Inflamm Bowel Dis 2005; 11: 42-47.

15 Selby WS: Current issues in Crohn's disease - finding the cause, making the diagnosis and optimising therapy. Med J Aust 2003; 178: $532-533$.

16 Cosnes J, Beaugerie L, Carbonnel F, Gendre JP: Smoking cessation and the course of Crohn's disease: an intervention study. Gastroenterology 2001; 120: 1093-1099.

17 van Maarle MC, Stouthard MEA, Marang-van de Meehn PJ, Klazinga NS, Bonsel GJ: How disturbing is it to be approached for a genetic cascade screening programme for familial hypercholesterolaemia? Psychological impact and screenee's views. Commun Genet 2001; 4: 244-252. 